\title{
Nunca aos domingos: um estudo sobre a temática do câncer nas emissoras de TV brasileiras
}

\author{
Never on Sundays: a study \\ of the topic of cancer on \\ Brazilian television stations
}

\section{Claudia Jurberg}

Jornalista do Intituto Oswaldo Cruz/Fudação Oswalco Cruz e do Instituto de Bioquímica Médica/ Universidade Federal do Rio de Janeiro (UFRJ) Av. Carlos Chagas Filho 373 - bl. H/sala H2003 21941-590 - Rio de Janeiro - RJ - Brasil cjurberg@bioqmed.ufrj.br

\section{Marina Verjovsky}

Doutoranda do Instituto de Bioquímica Médica/ Centro de Ciências da Saúde/UFRJ

Av. Carlos Chagas Filho 373, bl.H/H2003 21941-590 - Rio de Janeiro - RJ - Brasil verjovsky@bioqmed.ufrj.br
JURBERG, Claudia; VERJOVSKY, Marina. Nunca aos domingos: um estudo sobre a temática do câncer nas emissoras de TV brasileiras. História, Ciências, Saúde - Manguinhos, Rio de Janeiro, v.17, supl.1, jul. 2010, p.149-163.

\section{Resumo}

Analisa notícias sobre câncer no jornalismo da televisão brasileira, entre 2006 e 2007, resultando em 51 notícias exclusivas e 62 veiculações, em 12 diferentes emissoras nacionais de televisão (comerciais, educativas e fechadas). Os itens observados foram: origem (nacionais, internacionais); assunto (prevenção, diagnóstico, tratamento, cura, epidemiologia e/ou tabagismo); dia da semana e horários mais veiculados; características dos entrevistados; e ainda se as reportagens analisadas ofereciam aos espectadores explicações sobre fatores de risco e prevenção. Além disso, colheram-se depoimentos dos editores de telejornais das principais emissoras brasileiras. A análise dessas notícias e entrevistas evidenciou características relevantes da cobertura televisiva sobre temas de ciência e saúde, relacionadas aos critérios de seleção de pautas.

Palavras-chave: jornalismo científico; televisão; câncer; Brasil.

\section{Abstract}

The article analyzes news items about cancer on Brazilian tel evision, based on reports that aired in 2006 and 2007 , encompassing 51 exclusive news items and 62 airings on 12 national television stations (commercial, educational, and closed networks). The categories observed were: origin (national or international); subject matter (prevention, diagnosis, treatment, cure, epidemiology, and/or smoking); most common day of week and time of broadcast; characteristics of those interviewed; and whether theanalyzed reports offered viewers explanations on risk factors and prevention. Statements werealso taken from newsroom editors at Brazil's largest tel evision stations. The analysis of thesenews items and interviews revealed interesting features of tel evision coverage of science and health topics, which have to do with the criteria for defining news lineups.

Keywords: scientific journalism; television; cancer; Brazil. 
O Brasil foi o quarto país do mundo a possuir televisão. A primeira transmissão foi concretizada, através da PRF3-TV ou Canal 3, TV Difusora (futura Tupi de São Paulo), no dia 18 de setembro de 1950, às 22h, com uma hora de atraso. Os preparativos para a primeira transmissão consumiram quase um mês, porém não havia conteúdo para o segundo dia. Foi preciso aliar muita criatividade e correria para veicular o telejornal intitulado "Imagens do dia", no dia seguinte (Jurberg, 2001).

Para conseguir apoio ao seu projeto, Assis Chateaubriand reuniu, em 1947, vários patrocinadores que pagaram adiantado um ano de publicidade para custear a compra de uma estação de TV pela RCA (Squirra, 1990). Em razão do pequeno público fiel à televisão, nessa época, os anunciantes e as agências de propaganda preferiam o rádio, as revistas e os jornais para comunicar-se com os consumidores (Barbosa Lima, Priolli, Machado, 1985).

A formação de redes de televisão surgiu a partir dos anos 1960. A produção centralizouse entre as principais capitais brasileiras - Rio de Janeiro e São Paulo.

\title{
O impacto da televisão no Brasil de hoje
}

$\mathrm{Na}$ atualidade, a televisão continua a ser um dos eletrodomésticos mais desejados no seio da sociedade brasileira. Mais de $85 \%$ dos lares nacionais possuem ao menos um apareIho de televisão. De acordo com o Censo Demográfico 2000, elaborado pelo Instituto Brasileiro de Geografia Estatística, sobre as características dos lares brasileiros, há um empate técnico entre os aparelhos de rádio e de televisão (respectivamente $87,4 \%$ e $87 \%$ ). Em seguida, estão el etrodomésticos como a gel adeira ou freezer, presentes em $83 \%$ dos domicílios (Brasil, 2007).

Lino (2007) ressaltou, em pesquisa sobre a história da televisão no Brasil, que a baixa escolaridade, o alto analfabetismo e as acentuadas diferenças sociais tornam a televisão um dos principais veículos de produção, circulação e popularização de informação e conhecimento em toda a América Latina.

\begin{abstract}
se quisermos abordar conhecimentos que são compartilhados por toda a população podemos nos concentrar no que foi mostrado pela televisão, cuja linguagem éa mais difundida entre o público. Os programas de televisão constituem o mais popular passatempo; o ponto de referência básica para hábitose costumes; etambém o local onde as crianças são pel a primeira vez expostas a conceitos literários como al usão e sátira. (Bianculli, 1992; tradução livre).
\end{abstract}

Não se pode desprezar o fato de que a televisão é o primeiro meio de comunicação acessado por crianças a partir dos seis meses de idade e constitui veículo essencial de comunicação entre várias outras faixas etárias, se não em todas. Mesmo antes do aprendizado nas escolas, crianças mantêm contato permanente com esse el etrodoméstico (Koolstra, Bos, Vermeulen, 2006). Também podemos imaginar que numa sociedade em desenvolvimento, onde a Internet ainda é restrita e o jornal é muitas vezes aquisição supérflua, a tel evisão e o rádio são os veícul os mais eficazes, em termos de penetração, para a tran smissão de informações.

Embora a televisão seja um meio de comunicação que sofre críticas pelo pouco aprofundamento nas informações e pela possibilidade de efeitos negativos no aprendizado, 
Koolstra e colaboradores (Koolstra, Bos, Vermeulen, 2006), por outro lado, discutem ainda o efeito positivo da televisão no processamento e retenção da informação, em comparação com outras mídias. Estudos sobre a ‘memória de informações' preservada após a transmissão por diferentes veículos de comunicação - televisão, jornais e rádio - demonstram que os usuários de televisão têm maior grau de retenção das notícias, quando comparados aos ouvintes de rádio ou aos leitores de jornal. Esse índice favorável à televisão, segundo estudiosos, deve-se às associações de informações verbais e visuais em movimento, na televisão, em detrimento do único recurso do rádio, o som, e dos jornais, as informações e imagens estáticas.

\section{TV, ciência e saúde}

Em relação aos tópicos sobre saúde, ciência e tecnologia, Miller e colaboradores (2006) comentam que o interesse do público cresce à medida que os indivíduos envel hecem e, por outro lado, o aumento do interesse pela informação científica estimula a sua renovação, ou a procura por novos dados. É um ciclo que se mantém pela busca permanente de informação.

Os brasileiros estão cada vez mais interessados em temas de ciência e tecnologia, embora grande parcela ainda entenda pouco ou nada dos assuntos da área, conforme pesquisa recente do Ministério da Ciência e Tecnologia (MCT). O trabalho mostrou que o tema favorito da população é medicina e saúde, que o interesse em assuntos científicos é superior à política e que a população prefere receber informações sobre ciência intermediadas por jornalistas, para facilitar a compreensão da temática, considerada difícil (Moreira, Massarani, 2007).

Nisbet e colaboradores (2002) observaram que diferentes tipos de mídia (jornais, televisão em geral, tel evisão sobre ciência e revistas sobre ciência) afetam a percepção do público de formas diferentes. Os leitores de jornais, os que assistem canais sobre ciência e os que leem revistas sobre ciência têm uma visão mais positiva em relação à temática. A TV em geral tem uma audiência muito mais ampla, fornece visões positivas e negativas e sua capacidade de informar o público cientificamente não pode ser subestimada. Quando a educação formal acaba, a mídia se torna a principal fonte (às vezes, a única) para o público conseguir informações sobre descobertas científicas, controvérsias, eventos e o trabalho dos pesquisadores. Embora existam outras fontes, como museus e fontes interpessoais, nenhuma fornece tanto acesso como a mídia de massas.

Os meios de comunicação de massa são importantes veículos na divulgação de informações de saúde, para parcelas significativas da população (Barata, 1990), exercendo igualmente uma função social que ultrapassa o papel de apenas informar a sociedade (Darde, 2004). Diversos estudos (Tanner, 2004; Steele et al., 2005; Dixon et al., 2009; Hodgetts, Chamberlain, 1999) mostram que a televisão é a maior fonte de informações em saúde, para audiência tanto de leigos como de especialistas.

Apesar de ser um dosveículos com maior impacto em termos deaudiência, as transmissões de informações científicas não são ideais. Moreira e Massarani (2002), em estudo sobre o tema clonagem humana numa das novelas de maior audiência brasileira, 0 clone (TV Globo, 2001-2002), abordam que as mensagens sobre a ciência e os seus processos ainda 
são apresentadas de forma simplificada na TV brasileira. Para os autores, a imagem do cientista ainda é estereotipada: um homem com jaleco, imerso em seu laboratório e distanciado da realidade. Por outro lado, os autores destacam que, mesmo diante de imperfeições, a discussão sobre ética e os riscos da ciência foram primordiais no processo de divulgação científica para o grande público.

Para Siqueira (2008), a televisão pode despertar a atenção do público para o discurso científico, porém o uso que se faz do meio para a divulgação de ciências no Brasil é problemático. O meio televisivo se interessa pela comunicação da ciência, porém como ficção científica ou como apelo noticioso e sensacionalista. No formato jornalístico, o sensacionalismo configura-se um problema em matérias produzidas por jornalistas nem sempreafeitos ao discurso científico, com pouco tempo para produção, em veículos que abrem espaço exíguo para uma edição cuidadosa e veiculação de assuntos que precisam de explicação.

A pesquisa de Andrade (2004) sobre os noticiários de três grandes telejornais (dois brasileiros: Jornal da Record e Jornal Nacional; e um americano: World News Tonight) e a inserção de temas de ciência, tecnologia e saúde ressalta que a presença marcante dessas temáticas na vida das pessoas, nos dias atuais, tanto no Brasil como nos Estados Unidos, torna urgente a adoção de ações, nos meios de comunicação nacionais, pela busca da compreen são dos impactos desse desenvolvimento: "Os meios de comunicação de massa, como a televisão, não podem se manter al heios a esta realidade" (p.256).

Diversos estudos brasileiros mostram como a tel evisão é fonte importante de informações sobre câncer à população. Em pesquisa feita com mulheres de Goiânia (GO), a televisão foi apontada como principal fonte de informação sobre câncer de mama (26,5\% das entrevistadas), independentemente do grau de escolaridade ou renda familiar (Godinho, Koch, 2005). Outra aponta que, em um município do norte do Paraná, mulheres que agendaram exame de prevenção do câncer cérvico-uterino revelaram ter obtido informações de fontes impessoais como a televisão (Pelloso, Carvalho, Higarashi, 2004). Já um estudo extenso sobre câncer de boca, realizado em Taubaté (SP), também mostrou que as informações sobre o tema foram obtidas através da televisão (29,74\% dos entrevistados), antes mesmo da informação do profissional de saúde bucal (Quirino et al., 2006). Porém, nenhuma pesquisa antes publicada avaliou o conteúdo ou a abordagem de reportagens de noticiários brasileiros.

\section{Objetivo}

Este estudo vem se somar a outros três - "Na mira do câncer: o papel da mídia brasileira" (Jurberg, Gouveia, Sousa, 2006), “Um olhar sobre as revistas: o caso da divulgação em câncer" (Jurberg, Macchiute, 2006) e "Câncer nas ondas do rádio" (Jurberg, Macchiute, 2007) - e pretende avaliar alguns aspectos da popularização da temática do câncer na mídia brasileira, incluindo jornais, revistas, rádio e televisão. Nele procuramos averiguar, durante dois períodos distintos (novembro e dezembro de 2006 e abril e maio de 2007), o quantitativo da temática de câncer veiculado pelo telejornalismo brasileiro e o tratamento que o assunto recebe na televisão (canais abertos e fechados), uma vez que essa mídia é a principal via de informação da população brasileira. 
A escolha dos meses procurou comparar as notícias sobre câncer num período anterior ao verão e durante o outono, na região Sudeste, uma vez que o câncer de pele está intimamente relacionado ao sol e é o tipo mais frequente, correspondendo a cerca de $25 \%$ de todos os tumores malignos registrados no Brasil. Além disso, buscamos identificar as características das notícias sobre câncer everificar seas mesmas contribuem para desmistificar a doença, que ainda é associada a dor, morte e sofrimento (Hodgetts, Chamberlain, 2007). Também procuramos averiguar, com alguns produtores de tel ejornalismo, como éo processo de elaboração da escolha das notícias (a pauta), nas principais emissoras abertas em nosso país.

Diante dos resultados obtidos, junto com as outras mídias já analisadas nos outros estudos de nosso grupo, esperamos atuar de forma mais eficiente junto à imprensa brasileira na divulgação do tema câncer e, com isso, contribuir para tornar a sociedade brasileira uma importante aliada na prevenção e diagnóstico precoce da doença.

\section{Metodologia}

Realizou-se um levantamento quantitativo sobre todas as reportagens com a temática câncer, veiculadas entre novembro e dezembro de 2006 e abril e maio de 2007, excluindo dados e notícias de personalidades acometidas pela doença. Todos os outros assuntos foram engl obadas no estudo. As reportagens foram adquiridas de uma empresa fornecedora de notícias veiculadas pela tel evisão, a Clipping TV, empresa sediada no Rio de Janeiro, que monitora todos os canais exclusivos de notícias, abertos e fechados, e envia as notícias de acordo com a solicitação do cliente.

Verificou-se que reportagens sobre a temática câncer foram veiculadas nas emissoras Globo, Globo News, SBT, Bandeirantes, Record, Rede TV, Canal Futura, TV JB, Cultura, TV Brasil, TV Senado e TV Alerj, sendo as quatro últimas emissoras públicas. Pela grade de programação das emissoras de televisão, foram identificados 15 telejornais diurnos e 12 noturnos.

Foram exibidas, durante o período analizado (novembro e dezembro de 2006 e abril e maio de 2007), 51 reportagens exclusivas, que resultaram em 62 veiculações, pois al gumas reportagens foram ao ar mais de uma vez. Essa amostra foi estudada através do processo de decupagem - análise dos detalhes de cada matéria, onde se busca registrar em planilhas uma gama de itens, através de abordagem qualitativa. Portanto, este estudo baseou-se em análises quantitativas (número de reportagens, quantificação das unidades de contextos que elas contêm) e método qualitativo (análise do conteúdo das reportagens, observações das características relevantes nas reportagens veiculadas e separação em categorias).

Os itens observados variaram entre origem (nacionais, internacionais); assunto (prevenção, diagnóstico, tratamento, cura, epidemiologia e/ou tabagismo); dia da semana e horários mais veiculados; entrevistados (uma fonte ou mais de uma fonte) e o sujeito priorizado nas entrevistas veiculadas pelas reportagens na televisão (grupo formado por pacientes, familiares e população, ou representantes dos profissionais da saúde como médicos, enfermeiros, pesquisadores em oncobiologia); e, ainda, se as reportagens analisadas ofereciam aos leitores explicações sobre fatores de risco e prevenção da doença. 
No material produzido pelas emissoras de televisão, foram procurados termos (ou unidades de registro) inseridos em contextos (Bardin, 1977) que exemplificassem os assuntos divididos nas seguintes categorias: prevenção, diagnóstico, tratamento, cura, epidemiologia e tabagismo. Vale ressaltar que uma mesma reportagem poderia conter unidades de registro e contexto classificadas em mais de uma categoria, a exemplo de aspectos epidemiológicos e prevenção; tabagismo correlacionado a prognóstico e cura; diagnóstico precoce; tratamento e cura.

As unidades de registro e de contexto correlacionadas neste estudo foram:

- Prevenção: identificada por expressões e termos como "incentivar a prevenção", "visitar o médico para prevenir doenças", "exames preventivos" etc.;

- Diagnóstico: "exame”, "sintoma grave”, "fazer diagnóstico" etc.;

- Cura: "salvar a vida”, "nascer de novo", “doando vida”, “não estaria vivo hoje” etc.;

- Epidemiologia: "mais de dez mil mulheres morrem de câncer de mama todos os anos", "câncer de mama, o mais mortal entre as mulheres" etc.;

- Tratamento: "doação de medula", "tratamento longo", "tratamento precoce", "falta de medicamentos", "quimioterapia”, a máquina da quimioterapia”, “CTI" etc.;

- Tabagismo: "fumo", "cigarro", "fumante”, "viciado em cigarro" etc.

Posteriormente, entrevistamos os produtores dos telejornais das principais emissoras abertas brasileiras. Jornalistas da TV Globo, BandNews, TV Brasil, Sistema Brasileiro de Televisões (SBT) e Rede Record foram consultados com o propósito de averiguar o processo de seleção das notícias veiculadas em seus noticiários. As entrevistas foram realizadas por meio de telefone e correio eletrônico, e os jornalistas foram incentivados a responder como é produzida a pauta diária nos diferentes veículos e se os temas de ciência e saúde seguem a mesma ten dência de outros assuntos. Por último, para responder à nossa hipótese, os questionamos se havia alguma restrição a notícias sobre câncer nos finais de semana e festas de final de ano.

\section{Resultados e discussão}

\section{O fato como notícia}

A análise das reportagens evidenciou que, para a mídia televisiva cobrir o tema câncer, é importante a ocorrência de um fenômeno que estimule a sua veiculação, ou seja, reportagens baseadas no factual. Porém notícias que são atemporais também são divulgadas. O factual é o estímulo da notícia, é o que trata, por excelência, dos fatos ocorridos no mesmo dia em que a reportagem é veiculada, ou na semana ou no mês, quando são veículos semanais ou mensais. No entanto, nem toda notícia é baseada no factual. As pesquisas de laboratório, principalmente as de ciência básica (isto é, aquelas que visam a obtenção de conhecimento científico sem vislumbrar sua aplicação imediata), não resultam em notícias factuais e geralmente podem ir ao ar em qualquer dia - e não apenas no dia ou na semana em que foram realizadas. 
No caso das notícias factuais, o meio televisivo dá preferência aos alertas à população, como as campanhas de prevenção e os direitos dos pacientes, em detrimento de resultados de pesquisa científica da área. Isso pôde ser identificado principalmente no mês de novembro de 2006, quando 14 das 15 matérias veiculadas abordaram campanhas, em especial a campanha nacional empreendida pela Sociedade Brasileira de Dermatologia (SBD), no intuito de esclarecer a população sobre os perigos do câncer de pele.

Em abril de 2007, duas reportagens (em quatro veiculações) abordaram campanhas de prevenção de diversos tipos de câncer, além de duas outras que apontavam relações entre al imentação saudável e prevenção da doença. Nesse mês eem dezembro de 2006 destacaramse quatro matérias (duas em cada mês) que divulgaram ONGs e se detiveram por mais tempo do que o habitual na televisão (até 23 minutos, a mais longa), na exposição de dramas pessoais de pacientes e familiares.

Afinal, excetuando-se os programas temáticos sobre o câncer ou mesas-redondas com a presença de um especialista no assunto - e que podem chegar a até mais de 40 minutos -, em média as outras reportagens analisadas sobre o tema ocuparam cerca de dois minutos do telejornalismo nacional, tempo similar a outras temáticas - de futebol a política.

Em maio de 2007 também foram transmitidas apenas duas reportagens (em três veiculações) sobre campanhas de prevenção, porém outras três (em quatro veiculações) abordaram um projeto de lei que prevê um dia de folga para as mulheres fazerem exames de câncer de colo de útero e de mama. Só houve novamente um incremento na veiculação do tema nesse mês durante a divulgação de uma pesquisa realizada pelo Instituto Nacional do Câncer (Inca), acerca do que o brasileiro pensa a respeito da doença (e de que o relaciona a dor e morte). Nesse dia, $88,8 \%$ das matérias sobre câncer, veiculadas nos telejornais brasileiros, foram a respeito do estudo. Embora essa notícia aborde uma pesquisa acerca do câncer, tampouco relata resultado de pesquisa em biologia do câncer.

\section{Ciência na TV}

Poucas pessoas conheçam a fundo as pesquisas científicas, emenos ainda entendem por que estão sendo realizadas e qual o seu potencial e suas implicações. Apesar disso, os estudos e experimentos com os quaisoscientistas estão envolvidostêm profundos impactos na vida dos cidadãos de países desenvolvidos e em desenvolvimento.

(Field, Powell, 2001; tradução livre).

Episódios pontuais e pouco relevantes para a rotina científica acadêmica se tornam notícias. Mesmo esses temas poderiam ser mais explorados, pois em geral o dia a dia da veiculação rotineira em câncer se mostrou muito tímido (apenas 51 reportagens originais, nos quatro meses analisados).

Conforme afirmaram produtores dos telejornalismos da TV Brasil e TV Record, a sel eção das notícias que vai ao ar segue a tendência imposta pela mídia impressa, além do apelo público. Se os jornais impressos publicarem reportagem sobre câncer, a temática pode também ser veiculada na televisão: 
A pauta começa com a leitura diária dos jornais, e posteriormentea reunião de pauta para definição dos assuntos prioritários do dia... as escol hi das são as que têm mais apelo junto ao público alvo (M.M - TV Brasil).

Todos que trabal ham com jornalismo, princi palmente os produtores, buscam pautas nosjornais, revistas, e-mails, denúncias que chegam por tel efone, desdobramentos do factual, e no cotidiano. A importância de observar detal hes que para as outras pessoas passam despercebidos: uma nova moda, um novo costume etc. (T.L. - TV Record).

Para profissionais da BandNews e TV Globo, conforme os depoimentos, a escolha das notícias a serem veiculadas segue o seguinte princípio:

É preciso, antes de mais nada, pressupor interesse público. Quanto maior o interesse, mel hor se cumpre a função do jornal. Em seguida, pesam aspectos como ineditismo, potencial de imagem - um VT com bom apelo visual émel hor que sem ele (R.B. - Grupo Bandeirantes).

No caso de TV, há sempre preocupação com as imagens. Precisamos contar uma história através de imagens, e pesquisas científicas e de saúdenem sempreoferecem muito 'campo'. Temos informações, pessoas autorizadas a fal ar, mas nem sempre imagen s capazes de ilustrar ou traduzi r essas informações. Isso pode, muitas vezes, tran sformar um assunto atraente em chato (E.T. - TV Globo).

\section{Domingos e festas de final de ano}

Em relação ao quantitativo de exibições, por outro lado, pudemos observar que o mês de dezembro de 2006 foi atípico, com baixo nível de veiculações, o que pode ser associado aos festejos de fim de ano.

Com respeito à circulação entre os dias da semana, em todos os meses analisados verificamos que as reportagens sobre câncer circulam livremente entre os dias da semana, porém são restritas nos finais de semana. Os produtores do telejornalismo da TV Brasil e da TV Globo acreditam que a ausência de reportagens sobre câncer, nos finais de semana efestejos de fim de ano, deve-se às poucas sugestões recebidas pelos profissionais da emissora.

Geralmente, os profissionais mais gabaritados não estão disponíveis nesses dias [aos domingos]. As exceções são raras (M.M - TV Brasil).

Não consigo explicar, mas posso levantar algumas hipóteses. A primeira équedificilmente há receptividade de órgãos de ciên cia e saúde para gravações aos sábados e feriados de final de ano. Grande parte dos pesquisadores e da assessoria de imprensa não trabal ha nos fins desemana eferiados - como os do fim deano - eisso éum obstáculo ao trabal ho (E.T. - TV Globo).

À exceção do mês de novembro, quando ocorreu, em um sábado, campanha empreendida pela SBD para prevenção do câncer de pele, em todos os outros meses não foi observada veiculação de qualquer reportagem nesse dia da semana, e raros episódios (três) foram observados nos domingos. A esse respeito, uma produtora afirmou: "[A sel eção de pautas de ciência e saúde é feita] a partir de doenças mais incidentes ou desconhecidas. Também costumamos fazer matérias nos dias 'temáticos', reservados para alguma doença. Ou ainda quando há alguma pesquisa sobre temas relativos à área" (M.M - TV Brasil). 
Christofoletti (2006), em artigo sobre temáticas veiculadas num domingo em jornais catarinenses, sugere: “Afinal, a função dos jornais é evidenciar o que acontece pelo mundo e servir como um meio de expressão, seja de protestos ou não. Estes resultados servem para reavaliar um tema que geralmente é debatido em diversos círculos: que a mídia só sabe mostrar coisas ruins. Apesar do único dia de análise, mas com grande índice de leitores, dessa vez o dito não foi comprovado". Ou seja, a pesquisa demonstrou que na imprensa escrita de Santa Catarina, especificamente nos jornais Diário Catarinense, A Notícia e Jornal de Santa Catarina, a maior parte do material veiculado não tinha aspecto negativo. Esse dado corrobora nossas análises, que apontam espaço rarefeito para a temática câncer nos programas televisivos de domingo.

Assim como aos sábados e domingos evita-se dar notícias ruins aos leitores e tel espectadores, conforme apareceu em nossos resultados e em estudo de Christofoletti (2006), o fim do ano - período em que se comemoram o Natal e a chegada do ano-novo - também é restrito a temáticas tristes. De acordo com relatos da produção do telejornalismo da BandNews, "temas que remetam a doen ças são natural mente evitados". Porém, o jornalista R.B. afirma: "Jamais ouvi qualquer determinação formal nesse sentido, mas creio que minha dedução, a de que temas que remetam a doença sejam evitados, faz sentido". Na mesma diretriz, há os depoimentos dos produtores do telejornalismo da Rede Record (T.L.) e da TV Globo (E.T.) que afirmaram, respectivamente:

Duranteasfestas, as pautas de saúde, geralmente, precisam de pontos positivos- pessoas quevenceram a doença ou lutam para vencêla, tratamentosqueamenizam a dor, técnicas e cirurgias quetrazem esperança decura. Nessas ocasiões, as pessoas estão mais sensíveise querem ter boas notícias. As reportagen s sobre o câncer vão continuar sen do veiculadas, independente das datas. É preciso saber vender a pauta, buscar o lado mais interessante do assunto, pode ser um al erta; , uma campanha de conscientização (T.L. - TV Record).

Nesses dias o jornal tem um perfil mais leve, com uma cobertura menos factual instituições econômicas e políticas em geral não funcionam. Na hora de paginar o jornal, podeser que fuja um pouco do perfil do dia. De qualquer forma, matérias sobre câncer em geral têm uma via deorientação e muitas vezes estão associadas a descobertas científicas, o que as tornam mais levese compatíveis com os telejornais destes dias (E.T. - TV Globo).

\section{Ao público geral}

As análises das reportagens e dos relatos dos profissionais que decidem as notícias que serão veiculadas na televisão podem ser correlacionadas ao trabalho sociológico do pesquisador Pierre Bourdieu em seu livro Sobre a televisão, no qual critica a forma como as reportagens são eleitas pelos produtores, ao "nivelar por baixo" o suposto interesse do público:

Uma parte da ação simbólica da televisão, no plano das informações, por exemplo, consiste em atrair a atenção para fatos que são de natureza a interessar a todo mundo, dos quais se pode dizer que são omnibus - isto é, para todo mundo. Osfatos-ônibus são fatos que, como se diz, não devem chocar ninguém, quenão envolvem disputa, que não dividem, que formam consenso, que interessam a todo mundo, mas de um modo tal que não tocam em nada de importante. As notícias de variedades consistem nessa espécie 
elementar, rudimentar, da informação queéimportanteporque interessa a todo mundo sem ter consequências e porque ocupa tempo, tempo que poderia ser empregado para dizer outra coisa (Bourdieu, 1997, p.23).

Para ilustrar, reproduzimos o depoimento de E.T, produtor do jornalismo da TV Globo:

No caso das pautas de saúde, principalmente, há outro tipo de preocupação com imagens, que éo de não mostrar imagens que possam chocar demaisas pessoas. Cirurgias em andamento, grandes ferimentos etc. Há a preocupação também de o assunto ser o mais abrangente possível edespertar o interesse dos espectadores. Quando falamos desses assuntos, temos também a preocupação com o efeito que isso pode causar nas pessoas principalmente pessoas com doen ças crônicas ( E.T. - TV Globo).

Assim, esses profissionais de mídia dão preferência, especialmente nos finais de semana e épocas de festejo, a temas que consideram mais palatáveis, na tentativa de não 'chocar' o público com assuntos 'pesados' como o câncer. Tal quadro se agrava num panorama mais geral, no qual a cobertura diária da tel evisão evita, em certos momentos, temas densos como resultados de pesquisa científica em biologia do câncer - considerados de difícil entendimento pela população leiga e que, geralmente, não abrem espaço para a tentativa de aproximação emocional com o público pelas entrevistas com pacientes. Afinal, como afirmou o jornalista da BandNews (R.B.), um dos critérios na seleção de pautas de saúde e ciência é o componente humano: "Matérias com as quais as pessoas possam se identificar, nas quais possam ver histórias, situações que já viveram ou que podem vir a viver, são mais cobiçadas do que reportagens com especialistas falando, com gráficos, com autoridades em geral. Não que esses não possam ser incluídos, mas devem ser parte da história; coadjuvantes, não protagonistas".

E, de fato, identificamos nesta análise que o grupo formado por pacientes, familiares e população em geral teve mais destaque, se comparado aos profissionais da saúde. Ou seja, as reportagens veiculadas pela televisão, nos períodos analisados, prezaram por notícias que pudessem dar mais projeção ao cidadão comum do que aos especialistas da área. Isso implica, na prática, o desejo de aproximar o tema do público, em vez de apresentar uma informação científica (Gráfico 1).

Gráfico 1: Entrevistas com familiares de doentes e profissionais de saúde, em reportagens televisivas (nov.-dez. 2006; abr.-maio 2007)

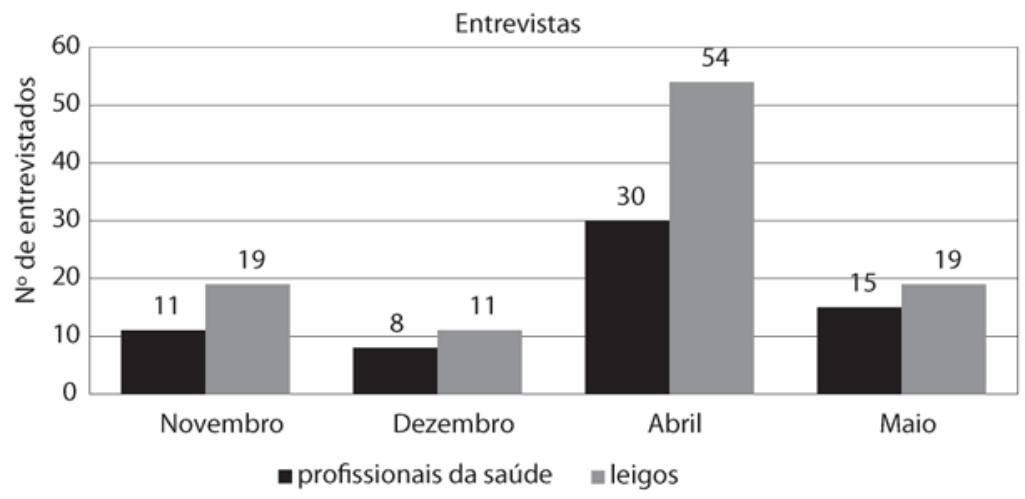


Isso ocorre porque os produtores acreditam que a opinião do cidadão ou a sua vivência no assunto dão veracidade à informação. Segundo León (2008), o importante é estabelecer uma conexão entre a informação científica e a experiência dos indivíduos. Nesse sentido, as reportagens sobre saúde que reflitam casos humanos podem contribuir para captar a aten ção dos telespectadores, pois estes tendem a fazer conexões com sua vivência. $O$ dado traz um diferencial em relação a outros veículos da mídia - jornais, revistas e rádio -, em que os profissionais da ciência e da saúde são escalados como protagonistas na interlocução entre a informação, a mediação e a sociedade. Em oposição, na tel evisão, o 'ator principal' é o paciente, seu familiar ou o cidadão. Sobre esse aspecto, a responsável pela elaboração da pauta do jornal do SBT, explica: “De alguns meses pra cá, o [programa jornalístico] prioriza matérias dramáticas - violência, dramas familiares, doentes sem assistência, por exemplo. O câncer pode ser pauta, dependendo do tom. O serviço pode até ser dado, mas depende do apelo do personagem" (P.T. - SBT). Assim, o tema câncer, nesse veículo da mídia, aparece apenas vinculado às pautas de saúde (que buscam maior apelo popular) em detrimento daquelas sobre ciência. A ciência, quando aparece, serve apenas como ferramenta de apoio (com gráficos, esquemas ou a fala do pesquisador), para 'respaldar cientificamente' uma informação sobre saúde que pretende ser transmitida.

\section{Abordagens}

Em relação aos tipos de câncer mais abordados, em novembro foi o de pele, fato que remete à campanha organizada pela SBD e também à proximidade com o verão em grande parte no país. Nos outros meses, observa-se a abordagem da doença de uma maneira geral, sendo que poucas são as reportagens que especificam um tipo de câncer. Resultado semel hante encontra-se em estudo sobre o tema veiculado nas revistas Saúde!, Veja e Pesquisa Fapesp (Jurberg, Macchiute, 2006), sendo que nos casos em que há a citação de um tipo prevaleceram os cânceres de mama, colo de útero e próstata (Gráfico 2).

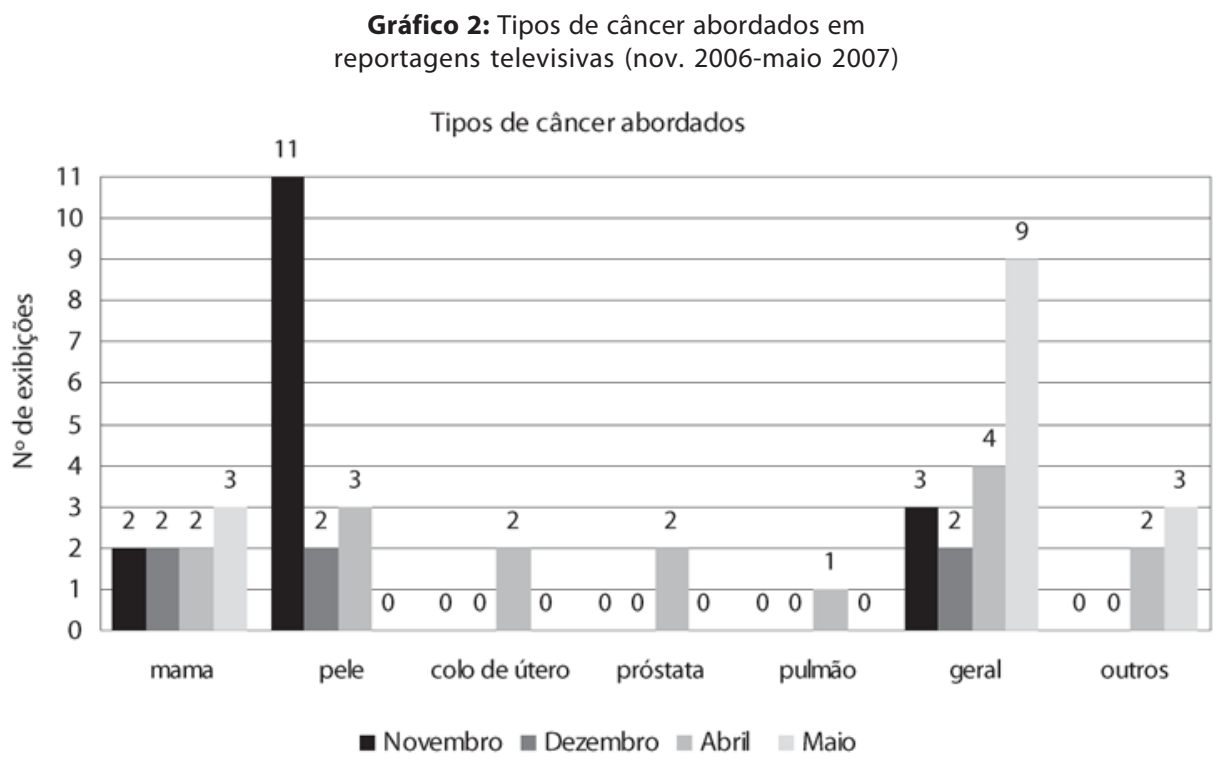


Ao verificarmos a tendência das reportagens em câncer, epidemiologia foi a abordagem mais divulgada (33\%), seguida por diagnóstico $(27 \%)$, campanha $(20 \%)$ e tratamento (17\%). Ao considerar apenas o mês de novembro, percebe-se que o tema campanha foi responsável por $42 \%$ das reportagens. Excetuando-se esse mês, atípico, as temáticas que mais permeiam a televisão brasileira são epidemiologia e diagnóstico precoce. Além disso, mais de $30 \%$ das reportagens sobre câncer, veiculadas pelos canais de televisão, abordaram fatores de risco da doença, e 50\% das reportagens citaram formas de prevenção ao câncer. Um exemplo pode ser conferido na seguinte frase de uma repórter: "A prevenção começa com hábitos de vida saudáveis, exercícios físicos e nada de cigarro" (BandNews, em 25 de maio de 2007).

O contraditório na divulgação científica expressa pela televisão foi identificado nessa correlação entre notícias sobre preven ção e abordagem dos fatores de risco. Se a prevenção é fundamental para evitar um câncer e a imprensa televisiva valoriza essa abordagem, por que apenas 30\% mencionaram fatores de risco? Com esses resultados, tornou-se claro que nem toda reportagem sobre prevenção também aborda fatores de risco e al ertas à sociedade. Um bom exemplo dessa correlação seria a divul gação do câncer de colo uterino e a ausência de explicações sobre o vírus do papiloma humano (HPV). Some-se a isso o fato de que, em caso de câncer, o diagnóstico precoce éfundamental quando se almeja um bom prognóstico. Nesse item, verificou-se que apenas $10 \%$ das reportagens de tel evisão que tratam do assunto câncer trouxeram informações sobre sintomas da doença.

Estudos de Dixon et al. (2009) já haviam demonstrado como o público pode reagir às controvérsias da medicina com foco específico em câncer e, nesse sentido, qual seria o papel da mídia. Eles defendem que incentivar o debate e esclarecer conflitos poderia ser uma importante ação em comunicação em saúde (fatores não identificados no presente estudo). Ainda segundo os autores, as evidências apontam que, no caso do câncer, o público leigo deve ser mais bem informado para enfrentar alguns conflitos intrínsecos à prática médica, para ser capaz de distinguir entre opinião e evidências. Assim, questionamos: por que não abordar fatores de risco e sintomas das doenças? Seria importante mostrar quais são as evidências e suas correlações e o que ainda é especulação em câncer, ou seja, o contraditório da ciência e a mutabilidade da medicina.

Hodgetts e Chamberlain (1999) também refletiram sobre essa intricada rede formada entre médicos e o entendimento público das doenças. Segundo os autores, a mediação de informações em saúde, pelo menos em parte, é realizada pela cobertura de mídia, que pode ser uma ferramenta apropriada para prevenir, detectar de forma precoce e contribuir para o tratamento eficaz contra o câncer, quando apresenta a importância da vida saudável, de seguir recomendações médicas etc.

\section{Outras análises}

Em relação aos horários preferenciais, pode-se afirmar que a maioria das notícias sobre câncer (59\%) é veiculada no horário nobre, ou seja, à noite, independentemente do mês analisado (Gráfico 3). Foi realizado levantamento que identificou 15 telejornais diurnos e 12 noturnos nas emissoras abertas, em que a programação comporta uma variedade de formatos (jornalísticos, educativos, filmes etc.). 
Gráfico 3: Horário de veiculação das reportagens televisivas sobre câncer (nov. 2006-maio 2007)

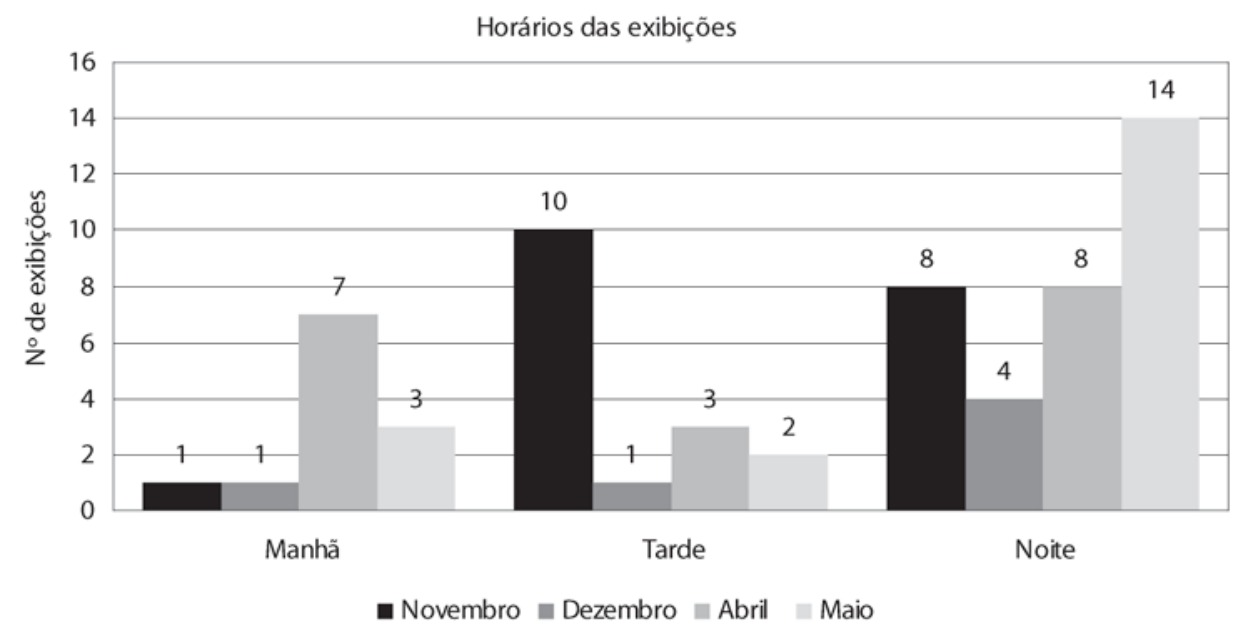

De modo geral, observou-se limitada exibição de uma mesma reportagem várias vezes. Contra a corrente, o canal de televisão aberta do grupo Bandeirantes foi o veículo que mais se utilizou dessa prática, sendo que em média uma mesma reportagem foi veiculada quatro vezes.

Quanto à origem das reportagens, 87,7\% tiveram como fonte de informação a pesquisa ou as campanhas nacionais. Portanto, as agências de notícias internacionais pouco influenciaram na veiculação de notícias sobre câncer, no período estudado. Nesse aspecto, o resultado encontrado também foi semel hante ao estudo que realizamos no rádio (Jurberg, Macchiute, 2007), cuja preferência é pela pesquisa nacional em detrimento de conteúdos enviado por agências de notícias. Vale ressaltar que não houve diferença significativa entre os dois períodos estudados.

\section{Conclusão}

Inexiste uma rotina sistemática na divulgação em câncer nas emissoras de televisão brasileiras. Matérias sobre o assunto são majoritariamente divulgadas quando há um fato novo que não seja cientificamente denso e que possa facilmente promover identificação emocional com o público, como quando há um serviço em saúde para ser ofertado aos telespectadores, conforme explicitado no depoimento da produtora de jornalismo do SBT (P.T.). Esse aspecto foi refletido na campanha para prevenção do câncer de pele, empreendida pela SBD, e sobressai nas reportagens selecionadas neste estudo.

Diante dos resultados en contrados nos depoimentos dos produtores de al guns tel ejornais brasileiros, e como já indicava a pesquisa do Inca - vastamente divulgada pela mídia televisiva em maio de 2007 -, podemos dizer que o câncer ainda é considerado, também pelos jornalistas, um tema desagradável e parece ser evitado nos finais de semana e próximo aos festejos de fim de ano. Apesar de sofrer cortes e restrições em determinados dias da semana, por outro lado, o horário nobre, das $20 \mathrm{~h}$ às $22 \mathrm{~h}$, é preferencial para as transmissões das reportagens sobre o assunto. 
A pesquisa científica em câncer ainda é pouco explorada por esse meio, que prefere abordar campanhas institucionais e reportagens sobre dramas humanos. O desenvolvimento de estudo sobre a descoberta de novos parâmetros da biologia do câncer recebeu pouco apoio desses veículos. Preferirão os pesquisadores envolvidos na temática a divulgação impressa e radiofônica e, por isso, ainda exploram de forma incipiente a inserção do tema na televisão brasileira? Ou é a própria indústria da televisão que evita o tema, por considerálo difícil demais para o seu público? Ou ambos?

Por fim, acreditamos que esses dados, juntamente com os estudos real izados anteriormente sobre a temática câncer e sua veiculação em outras mídias (rádio, revistas e jornais), poderão auxiliar os especialistas na área (médicos, pesquisadores e outros profissionais) e os divulgadores de ciência numa ação conjunta para desenvolver novas pautas, atrair outros parceiros na luta pela prevenção do câncer e, consequentemente, esclarecer devidamente a população sobre o assunto.

\section{AGRADECIMENTOS}

Agradecemos o inestimável apoio das doutoras Vivian M. Rumjanek e Ottília Affonso Mitidieri, pela visão crítica e pelas sugestões, incorporadas no texto, como também ao Banco Icatu e a dona Vivi Nabuco, que possibilitam as estratégias empreendidas pelo Núcleo de Divulgação do Programa de Oncobiologia, do Instituto de Bioquímica Médica da Universidade Federal do Rio de Janeiro.

\section{REFERÊNCIAS}

ANDRADE, Lacy Varella Barca de. Iguarias na hora do jantar: o espaço da ciência no telejornalismo diário. Tese (Doutorado) Programa de Pós-graduação em Bioquímica Médica, Instituto de Ciências Biomédicas, Universidade Federal do Rio de Janeiro, Rio de Janeiro. 2004.

BARATA, Rita de Cássia Barradas. Saúde e direito à informação. Cadernos de Saúde Pública, Rio de Janeiro, v.6, n.4, p.385-399. 1990.

BARBOSA LIMA, Fernando; PRIOLLI, Gabriel; MACHADO, Arlindo.

Televisão \& vídeo. Rio de Janeiro. Jorge Zahar. 1985.

BARDIN, Laurence.

Análise de conteúdo. Lisboa: Edições 70. 1977.

BIANCULLI, David.

Teleliteracy: taking television seriously. New York: Touchstone Books.1992.

BOURDIEU, Pierre.

Sobre a tel evisão. Rio de Janeiro: Jorge Zahar. 1997.

\section{BRASIL.}

Ministério do Planejamento, Orçamento e Gestão. Instituto Brasileiro de Geografia
Estatística. Nosso povo: famílias e domicílios. Disponível em: http://www.ibge.gov.br/7a12/ conhecer_brasil/default.php?id_tema_menu $=2$ \&id_tema_submenu=7. Acesso em: 18 jun.

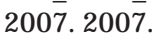

CHRISTOFOLETTI, Rogério.

Notícias boas, notícias ruins: singularidades catarinenses. Intercom N otícias, São Paulo, ano 2, n.42. Disponível em: http://www.intercom. org.br/boletim/a02n42/forum_monitor.shtml. Acesso em: 3 set. 2007. 2006

DARDE, Vicente William da Silva.

A Aids na imprensa: a construção da imagem da epidemia e a influência na promoção da cidadania. Em Questão, Porto Alegre, v.10, n.2, p.247-259. 2004.

DIXON, Helen et al.

The prostate cancer screening debate: public reaction to medical controversy in the media. Public Understanding of Science, Calgary, v.18, n.1, p.115-128. 2009.

FIELD, Hyman; POWELL, Patricia.

Public understanding of science versus public understanding of research. Public Understanding of Science, Calgary, v.10, n.4, p.421-426. 2001.

GODINHO, Eduardo Rodrigues; $\mathrm{KOCH}$, Hilton Augusto. 
Fontes utilizadas pelas mulheres para aquisição de conhecimentos sobre câncer de mama. Radiologia Brasileira, São Paulo, v.38, n.3, p.169-173. 2005.

HODGETTS, Darrin; CHAMBERLAIN, Kerry. Concepção dos brasileiros sobre o câncer. Disponível em: http://www.inca.gov.br/ impressao.asp?op=pr\&id=1396. Acesso em: 23 out. 2009. 2007.

HODGETTS, Darrin; CHAMBERLAIN, Kerry. Medicalization and the depiction of lay people in television health documentary. Health, London, v.3, n.3, p.317-333. 1999.

JURBERG, Claudia.

Ciência na TV: um erro histórico. In: Congresso Brasileiro da Comunicação, 24., 2001, Campo

Grande. Anais... Campo Grande: Sociedade Brasileira de Estudos Interdisciplinares da Comunicação. Disponível em: http:// www.intercom.org.br/papers/nacionais/2001/ papers/NP9JURBERG.PDF. 2001.

JURBERG, Claudia; GOUVEIA, Maria Emerick; SOUSA, Camila.

Na mira do câncer: o papel da mídia brasileira. Revista Brasileira de Cancerologia, Rio de Janeiro, v.52, n.2, p.139-146. 2006.

JURBERG, Claudia; MACCHIUTE, Bruno. Câncer nas ondas do rádio. Revista Brasileira de Cancerologia, Rio de Janeiro, v.53, p.291-296. 2007.

JURBERG, Claudia; MACCHIUTE, Bruno. Um olhar sobre as revistas: o caso da divulgação em câncer. Revista Brasileira de Ciência da Comunicação, São Paulo, v.29, n.2, p.103-118. 2006.

KOOLSTRA, Cees M.; BOS, Mark J.W.; VERMEULEN, Ivar E.

Through which medium should science information professionals communicate with the public: television or the internet?. Journal of Science Communication, Trieste, v.5, n.3, p.1-8. 2006.

LEÓN, Bienvenido.

Science related information in European television: a study of prime-time news. Public Understanding of Science, Calgary, v.17, n.4, p.443-460. 2008.

LINO, Sônia Cristina.

História e imagem: 50 anos de televisão no Brasil. Encontro Nacional de História Oral, 6 , 2002, São Paulo. Anais... . Em CDRom. 2002.
MILLER, Jon D. et al.

Adult science learning from local television newscasts. Journal of Science Communication, Trieste, v.28, n.2, p.216-242. 2006.

MOREIRA, Ildeu de Castro; MASSARANI, Luisa.

Percepção pública da ciência e tecnologia. Brasília: Ministério da Ciência e da Tecnologia. Disponível em: http://www.mct.gov.br/ upd_blob/0013/13511.pdf. Acesso em: 16 nov. 2007. 2007.

MOREIRA, Ildeu de Castro; MASSARANI, Luisa. O clone [The clone]. Public Understanding of Science, Calgary, v.11, n.2, p.207-208. 2002.

NISBET, Matthew C. et al.

Knowledge, reservations, or promise?: a media effects model for public perceptions of science and technology. Communication Research, v.29, n.5, p.584-608. Disponível em: http:// crx.sagepub.com/cgi/reprint/29/5/584. Acesso em: 20 maio 2010. 2002.

PELLOSO, Sandra Maria; CARVALHO, Maria Dalva de Barros; HIGARASHI, Leda Harumi. Conhecimento das mulheres sobre o câncer cérvico-uterino. Acta Scientiarum. Health Sciences, Maringá, v.26, n.2, p.319-324. 2004.

QUIRINO, Maria Rozeli de Souza et al. Avaliação do conhecimento sobre o câncer de boca entre participantes de campanha para prevenção e diagnóstico precoce da doença em Taubaté. Revista de Odontologia da UNESP, São Paulo, v.35, n.4, p.327-333. 2006.

SIQUEIRA, Denise da Costa Oliveira. Televisão e divulgação científica. Com Ciência, Campinas, n.100, Disponível em: http://www.comciencia.br/comciencia/ index. php? section $=8 \&$ edicao $=37 \& i d=444$. Acesso em: 08 nov. 2009. 2008.

STEELE, Whitney Randolph et al. News media coverage of a women's health controversy: how newspapers and TV outlets covered a recent debate over screening mammography. Journal of Women and Health, New York, v.41, n.3, p.83-97. 2005.

SQUIRRA, Sebastião.

A prender telejornalismo: produção e técnica. São Paulo: Brasiliense. 1990.

TANNER, Andrea $\mathrm{H}$. Agenda building, source selection, and health news at local television stations. Science Communication, Thousand Oaks, v.25, n.4, p.350-363. 2004.

\section{u uUUUU}

